\title{
Margaret McCartney: Meet the Robodocs: resilient automatons who do as they're told
}

\author{
Margaret McCartney general practitioner, Glasgow
}

"I am struck by how much the military invest in resilience training," said Terence Stephenson, the new chair of the General Medical Council, at a recent hearing of the House of Commons Health Committee. He went on to say, “. . . they do not wait until they are out in Helmand province; they start at recruitment and training."

He added, "That is probably something that we could think about exploring ... building in resilience training when people are medical students and young trainees rather than waiting. . . until you've been reported or had a complaint, and then trying to develop that resilience."

At last: joined up health policy. Let's forget the hostile, overcrowded hospital terrain; the tanks of revalidation and the friends and family test on the lawn; and the inaccurate aim of the Care Quality Commission's bullets. With special resilience training, you too can learn to stop complaining and start coping. You can see more patients with more complex problems, superfast and stress-free. Why worry so much about the associations between reduced staffing and patient mortality ${ }^{23}$ or indeed that in England hospital beds fell in number by $59 \%$ from 1979 to $2012^{4}$ despite our ageing, multimorbid population?

It can hardly be a coincidence that Simon Stevens, NHS England's chief executive, chose the same week to announce that primary care doctors will be available instantly for online video chat with their younger patients because "the idea of booking appointments and physically turning up to their GP surgeries for routine things is an alien concept." Instead, they can "call up a doctor or a nurse on [their] iPhone and have the face to face interaction there" the young people around here are of interacting with their GPs in real time and real life.

It's clear where policies like this will eventually lead: Robodocs. These automatons will have resilience of steel and will unquestionably follow the instructions of higher powers. Clinical examinations and smear tests will be done by robots delivered by drone, and empathy will be delivered, in response to a patient's distressed tones, by a head nodding device approved by the Royal College of General Practitioners.

Targets for handwashing will be met as standard. So will smoking cessation advice targets, because it will not be possible to proceed to the correct diagnosis protocol until it has been offered, even if the patient is moribund.

The only problems with this new policy will be when we have clinical uncertainty; when it is not possible to be sure of what to do; or when patients want to talk to a human being with feelings - to be listened to and heard, or to have someone bear witness to their life - as, curiously, they often do. Humans who are doctors also feel pain, and no amount of resilience training can make our hearts mechanical.

Competing interests: I have read and understood the BMJ policy on declaration of interests and declare the following interests: I'm an NHS GP partner, with income partly dependent on Quality and Outcomes Framework points. I'm a part time undergraduate tutor at the University of Glasgow. I've written two books and earn from broadcast and written freelance journalism. I'm an unpaid patron of Healthwatch. I make a monthly donation to Keep Our NHS Public. I'm a member of Medact. I'm occasionally paid for time, travel, and accommodation to give talks or have locum fees paid to allow me to give talks but never for any drug or public relations company. I was elected to the national council of the Royal College of General Practitioners in 2013 and am chair of its standing group on overdiagnosis. I have invested a small amount of money in a social enterprise, Who Made Your Pants?

The BMS's readers can buy Margaret's new book, Living with Dying, for $£ 7.99$ (RRP £11.99) including UK delivery from www.pinterandmartin. com with checkout code BMJ799.

Provenance and peer review: Commissioned; not externally peer reviewed.

1. House of Commons Health Committee. Accountability hearing with the GMC. 6 Jan 2015 www.parliamentlive tv/Main/Player aspx?meetingld $=16853$

Kane RL, Shamilyan TA, Mueller C, Duval S, Wilt TJ. The association of registered nurse staffing levels and patient outcomes: systematic review and meta-analysis. Med Care 2007;45;1195-204.

3 Keogh B. Review into the quality of care and treatment provided by 14 hospital trusts in England: overview report. 16 July 2013. www.nhs.uk/NHSEngland/bruce-keogh-review/ Documents/outcomes/keogh-review-final-report.pdf.

4 Appleby J. The hospital bed: on its way out? BMJ 2013:346:f1563.

5 Neville S. New towns will be testbeds for healthcare revolution. Financial Times 4 Jan 2015. www.ft.com/cms/s/0/53f89f00-91ce-11e4-afd2-00144feabdc0.htm|\#axzz3Qlgf2wou. 
